\title{
CJASN
}

Clin J Am Soc Nephrol. 2017 Jul 7; 12(7): 1128-1138.

PMCID: PMC5498355

Published online 2017 Jun 19.

PMID: 28630081

doi: 10.2215/CJN.11141016: 10.2215/CJN.11141016

\section{Calcium-Sensing Receptor Genotype and Response to Cinacalcet in Patients Undergoing Hemodialysis}

\author{
Sharon M. Moe, ${ }^{\mathbb{D}^{*} \dagger}$ Leah Wetherill, ${ }^{\ddagger}$ Brian Scott Decker, ${ }^{*}$ Dongbing Lai, ${ }^{\ddagger}$ Safa Abdalla, ${ }^{\S}$ Jin Long, ${ }^{\S}$ Matteo Vatta, ${ }^{\ddagger}$ \\ Tatiana M. Foroud, ${ }^{\ddagger}$ and Glenn M. Chertow ${ }^{\S}$ \\ "Division of Nephrology, Department of Medicine and

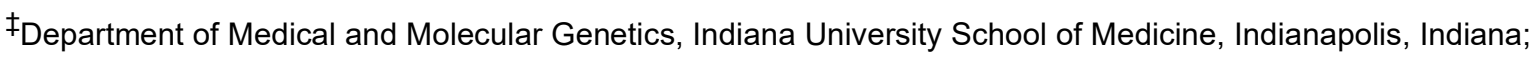 \\ ${ }^{\dagger}$ Department of Medicine, Roudebush Veterans Administration Medical Center, Indianapolis, Indiana; and \\ §Division of Nephrology, Department of Medicine, Stanford School of Medicine, Stanford, California \\ ${ }^{\circledR}$ Corresponding author.
}

Correspondence: Dr. Sharon M. Moe, Division of Nephrology, Indiana University School of Medicine, 950 West Walnut Street, R2-202 Indianapolis, IN 46202. Email: smoe@iu.edu

Received 2016 Oct 26; Accepted 2017 Mar 23.

Copyright $\odot 2017$ by the American Society of Nephrology

\section{Abstract}

\section{Background and objectives}

We tested the hypothesis that single nucleotide polymorphisms (SNPs) in the calcium-sensing receptor $(C A S R)$ alter the response to the calcimimetic cinacalcet.

\section{Design, setting, participants, \& measurements}

We analyzed DNA samples in the Evaluation of Cinacalcet $\mathrm{HCl}$ Therapy to Lower Cardiovascular Events (EVOLVE) trial, a randomized trial comparing cinacalcet to placebo on a background of usual care. Of the 3883 patients randomized, 1919 (49\%) consented to DNA collection, and samples from 1852 participants were genotyped for $18 C A S R$ polymorphisms. The European ancestry (EA; $n=1067)$ and African ancestry (AfAn; $n=405$ ) groups were assessed separately. SNPs in CASR were tested for their association with biochemical measures of mineral metabolism at baseline, percent change from baseline to 20 weeks, and risk of clinical fracture as dependent variables.

\section{Results}

There were modest associations of CASR SNPs with increased baseline serum parathyroid hormone and bone alkaline phosphatase primarily with the minor allele in the EA group (all $P \leq 0.03$ ), but not in the AfAn sample. In contrast, there was a modest association of decreased baseline serum calcium and FGF23 with $C A S R$ SNPs $(P=0.04)$ primarily with the minor allele in the AfAn but not in the EA sample. The minor allele of two SNPs was associated with decreased percent reduction in parathyroid hormone from baseline to 20 weeks in the EA population $(P<0.04)$ and this was not altered with cinacalcet. In both EA and AfAn, 
the same SNP (rs9740) was associated with decreased calcium with cinacalcet treatment (EA and AfAn $P \leq 0.03)$. Three SNPs in high linkage disequilibrium were associated with a higher risk of clinical fracture that was attenuated by cinacalcet treatment in the EA sample $(P<0.04)$.

\section{Conclusions}

These modest associations, if validated, may provide explanations for differences in CKD-mineral bone disorder observed in EA and AfAn populations, and for differential biochemical responses to calcimimetics.

Keywords: human genetics, calcium sensing receptor, fracture, FGF23, single nucleotide polymorphisms, Alkaline Phosphatase, Alleles, calcium, Chronic Kidney Disease-Mineral and Bone Disorder, Cinacalcet Hydrochloride, DNA, Genotype, Humans, Linkage Disequilibrium, Minerals, parathyroid hormone, Polymorphism, Single Nucleotide, Receptors, Calcium-Sensing, renal dialysis

\section{Introduction}

Complications of moderate to advanced CKD include a variety of disorders of mineral metabolism. Associated clinical manifestations, termed CKD-mineral bone disorder (CKD-MBD [1,2]), include bone disease (with an increased risk of fracture), cardiomyopathy, anemia, pruritus, extraskeletal calcification, and increased risks of mortality, heart failure, and other cardiovascular events $(\underline{3}, \underline{4})$. Treatment of secondary hyperparathyroidism can attenuate many of these manifestations. Treatment options include the use of pharmacologic doses of 1,25 dihydroxy vitamin D (calcitriol) or related analogs, the calcimimetic cinacalcet, and parathyroidectomy. Optimizing the approach for patient care through genomics to predict individual risk may help clinicians choose appropriate treatments.

Calcimimetics are allosteric activators of the calcium-sensing receptor (CASR). Cinacalcet (Sensipar/Mimpara) has been shown to lower serum parathyroid hormone (PTH), calcium, and phosphorus in patients undergoing dialysis $(\underline{5}, \underline{6})$. In the Evaluation of Cinacalcet $\mathrm{HCl}$ Therapy to Lower Cardiovascular Events (EVOLVE) trial $(\underline{7}, \underline{8}), 3883$ individuals were randomized to either cinacalcet or placebo in addition to standard of care treatments, which typically included phosphate binders and calcitriol or its analogs. In the trial, $24 \%$ of patients in the placebo arm and $12 \%$ of patients in the cinacalcet arm had severe unremitting hyperparathyroidism, demonstrating that some patients did not respond to cinacalcet treatment (7). Other studies have demonstrated that blacks with CKD have higher PTH concentrations compared with other races, suggesting altered response to pharmacotherapy $(\underline{9}, \underline{10})$. One possible explanation for these observations is genetic variability. We therefore examined the association of genetic polymorphisms in the $C A S R$ and vitamin D receptor $(V D R)$ genes and biochemical and clinical outcomes using stored biospecimens and clinical trial outcomes data from the EVOLVE trial.

\section{Materials and Methods}

Patients enrolled in the EVOLVE trial $(7, \underline{8})$ were asked to consent for collection of DNA at the baseline visit. The EVOLVE trial was a global trial with individuals enrolled from 22 countries ( $\underline{8})$. Of the 3883 participants enrolled in the EVOLVE trial, 1919 (49\%) consented to have DNA collected. The blood samples were processed by the central study laboratory (Covance, Princeton, NJ), and before release to Indiana University the trial sponsor, Amgen, confirmed appropriate institutional review board approval at each site for DNA collection, and separate informed consent for DNA collection and use. After DNA extraction, 1852 (97\%) of samples were of initial adequate quality to be genotyped.

\section{Genotyping}

On the basis of previously published literature, one single nucleotide polymorphism (SNP) in $V D R(\underline{11}, \underline{12})$ 
and 18 SNPs in CASR (13-16) were genotyped to ensure the entire gene could be evaluated for evidence of association. For quality assessment, additional SNPs were genotyped on the $\mathrm{X}$ and $\mathrm{Y}$ chromosomes to confirm self-reported sex. Only samples with an SNP genotype rate $>90 \%$ (seven samples excluded), and $\mathrm{X}$ - and Y-linked SNPs confirming self-reported sex (33 samples excluded) were retained. The remaining 1812 samples were included for analyses.

Race provided by each EVOLVE trial participant was used for race-based group assignments. Only the European ancestry (EA) and African ancestry (AfAn) groups were analyzed because of small numbers and heterogeneity in the other groups. There was no significant deviation from Hardy-Weinberg equilibrium for any SNPs in either racial group (all $P>0.01$ ). Linkage disequilibrium (LD) was estimated in each racebased group (Figure 1, A and B) and compared with the appropriate HapMap samples to ensure that the selected SNPs provided complete coverage of the gene.

\section{Statistical Analyses}

Because of admixture within the AfAn sample and differences in allele frequency between the EA and AfAn samples, all analyses were conducted in these cohorts separately. All nongenetic analyses and phenotype calculations were performed in SAS v9.4. We log-transformed all baseline laboratory variables before inference testing. Because the underlying genetic model was unknown, additive genetic models implemented in PLINK v1.07 (http://pngu.mgh.harvard.edu/purcell/plink/) (17) were used in all genetic analyses. This model assumes a similar increase (or decrease) in phenotype value for each copy of an allele. Because of the correlation of SNPs within CASR, we did not correct for the number of SNPs tested. The phenotypes examined in this study were chosen on the basis of previously reported literature. Initial analyses report the nominal association results and secondary analyses considered a correction for the six phenotypes, resulting in a corrected $\alpha=0.008$.

We employed linear regression including SNPs in all models and considered covariates individually, using forward stepwise regression with a stay criterion set at $P=0.10$. Covariates tested in this initial phase included age, sex, baseline calcium-containing phosphate binder use, and natural log-transformed baseline values of prior duration of dialysis (months), vitamin D use, bone-specific alkaline phosphatase (BALP) (nanogram per milliliter), intact PTH (picogram per milliliter), phosphorous (milligram per deciliter), and serum $\mathrm{N}$-telopeptide (nanomole bone collagen equivalents per liter), excluding the baseline measure of interest. We first tested for association of SNPs in the CASR and $V D R$ genes with baseline laboratory values for calcium (corrected for albumin), PTH, fibroblast growth factor 23 (FGF23), phosphate, and BALP after adjustment for covariates significantly associated $(P<0.10)$ with the modeled dependent variable. To increase power, residuals obtained from regression models implementing the appropriate covariates were employed in further genetic analysis. /because of the skewed baseline values, the natural log of all laboratory values was used for baseline analyses to obtain approximately normal distributions.

In the EVOLVE trial, samples were obtained at week 20, 52, and 104. At 20 weeks, $>90 \%$ of patients remained on their original treatment assignment, and the majority of patients had samples drawn at this time point. We therefore tested for association of the SNPs with percent change in calcium, phosphorus, PTH, and FGF23 from baseline to 20 weeks. Age and baseline values were included in all percent change analyses, regardless of $P$ value, and residuals were computed for each variable as described above. A linear regression model was employed in PLINK, using the residuals. Randomized treatment and an interaction term for SNP $\times$ randomized treatment were included in this step, to determine if SNP genotype altered the response to cinacalcet in the treatment group compared with the placebo group. Finally, given that secondary hyperparathyroidism alters bone metabolism and CASR is expressed in bone (18), we tested for association of SNPs in CASR and $V D R$ with risk of fracture using logistic regression models in PLINK (17). Forward logistic regression analyses were implemented as above, considering covariates previously 
shown to be associated with cardiovascular events and fracture risk in the EVOLVE trial $(19,20)$.

Covariates and randomized treatment were included in the logistic regression model in PLINK. As described above, treatment and an interaction term for $\mathrm{SNP} \times$ treatment were included to test if fracture outcome differed by SNP, in the presence of treatment.

\section{Results}

Baseline characteristics of the EA and AfAn patients with DNA samples compared with the individuals of other ancestry and the entire EVOLVE trial are shown in Table 1. A total of 59\% of participants with DNA were EA ( $n=1067)$ and $22 \%$ were AfAn $(n=405)$. Overall, $37.7 \%$ of the samples were collected from individuals in the United States, 4.3\% from Canada, 33.9\% from Europe, 22.8\% from Latin America, and the remaining from other geographical regions.

Summary data for SNPs in CASR and VDR are provided in Supplemental Table 1 and Tables 2 and $\underline{3}$. All SNPs had a missing rate of $\leq 0.2 \%$. Minor allele frequencies (MAF) in both the EA and AfAn samples were comparable to the MAF of white Europeans in Utah, Yorubans in Ibadan (Nigeria), and AfAn in the Southwest HapMap samples in the SNP Database hosted by the National Center for Biotechnology Information. Because of the limited power to detect association, SNPs with MAF $<0.05$ within each racial group were excluded from analyses. The LD plots for each racial group are shown in Figure 1 . There were no significant associations with the $V D R$ SNP and any phenotype (all $P>0.2$ ), so only $C A S R$ results are presented.

\section{Associations of CASR SNPs with Baseline and Percent Change in CKD-MBD Laboratory Values}

Tables 2 and $\underline{3}$ show associations of $C A S R$ SNPs with baseline laboratory values. In the EA population, the strongest associations were observed with the missense variant rs1042636 (R990G) and baseline serum PTH $(P<0.01$; AA genotype; $n=937$, mean- $\pm-S D: 813.6 \pm 1123.4$ versus AG/GG $n=148,904.6 \pm 178.8$ $\mathrm{pg} / \mathrm{ml}$ ), as well as the missense polymorphism rs1801725 (A986S) with baseline serum phosphate ( $P=0.03$; GG genotype $n=760,6.5 \pm 2.2$ versus GT/TT $n=326,6.7 \pm 0.9 \mathrm{mg} / \mathrm{dl})$, and baseline serum PTH $(P=0.02$; GG genotype $940.3 \pm 697.5$ versus GT/TT $871.7 \pm 925.8 \mathrm{pg} / \mathrm{ml})$. In the AfAn population, neither of these SNPs were associated with baseline laboratory values $(P>0.06)$; for the remaining $C A S R$ SNPs, the strongest association in the AfAn population was observed with rs1393199 and baseline phosphorus $(P<0.001$; AA genotype $6.2 \pm 1.15$ versus $\mathrm{AC} / \mathrm{CC} 6.5 \pm 1.17 \mathrm{mg} / \mathrm{dl})$ and rs4300957 and baseline calcium $(P=0.01$; CC genotype $n=328,9.6 \pm 1.09$ versus CT/TT $n=85,9.8 \pm 0.28 \mathrm{mg} / \mathrm{dl})$. Modest associations were also observed with other SNPs and baseline BALP in the EA population $(P<0.02)$ and baseline FGF23 and calcium in the AfAn population $(P \leq 0.04)$.

The association of the CASR SNPs and percent change in PTH, phosphorus, and FGF23 from baseline to week 20 was examined, adjusted for baseline covariates significantly associated with each biochemical variable (Supplemental Tables 2 and 3). One extreme value of FGF23 change was winsorized to the 90th percentile value of 700. As seen in Figure 2, there was a modest association of rs937627 genotype with percent change in PTH in the EA population (Figure 2A; $P=0.04$ ), but no significant interaction with treatment $(P=0.06)$. There was no association of $C A S R$ SNPs with changes in FGF23 or phosphorus (all $P \geq 0.08$ ). In contrast, in the AfAn population there was an interaction of rs 203699 genotype and treatment for percent change in FGF23; treated individuals homozygous for the major allele had a negative percent change compared with individuals with at least one copy of the minor allele, who had positive values ( Figure 2B; $P=0.01$ ). There was also an interaction of rs 1393199 and treatment for percent change in calcium; homozygotes for the major allele had a greater decrease in response to cinacalcet (rs1393199; $P=0.04)$. One SNP rs9740 demonstrated an interaction between genotype and treatment for percent change in calcium in both the EA $(P=0.03$; Figure $2 \mathrm{C})$ and AfAn $(P=0.02$; Figure $2 \mathrm{D})$ populations: homozygotes 
for the major allele had a greater decrease in response to cinacalcet.

\section{Associations of CASR SNPs with Fractures}

We assessed association of $C A S R$ and the VDR SNP genotypes and a clinical (symptomatic) fracture that occurred after randomization in the EVOLVE trial. There was no significant association of any of the SNPs and fracture in the AfAn population (all $P>0.11$ ). However, in the EA population, there was an association of three SNPs in CASR (rs4678044, rs4300957, and rs7647446), all in high LD (pairwise $r^{2} \geq 0.89$ ), and the risk of fracture (all $P<0.04$ ) adjusted for history of fracture, sex, and natural log of intact PTH. Treatment was included in the model as a main effect for both populations. For these three SNPs, the odds of experiencing a fracture increased by approximately $45 \%$ for each copy of the minor allele. Figure 3 demonstrates this finding for SNP rs7647446: patients homozygous for the minor allele AA had an increased association of higher risk of fracture that was reduced with cinacalcet treatment (treatment adjusted odds ratio, $0.47 ; 95 \%$ confidence interval, 0.24 to $0.93 ; P=0.03$ ). There was no association of fracture with the $V D R$ SNP in either population (both $P>0.24$ ).

When considering correction for the evaluation of six phenotypes, only baseline changes of serum PTH in the EA population (rs 1042636), as well as serum phosphorous (rs1393199) and calcium (rs4300957) in the AfAn population meet the threshold of $P<0.01$.

\section{Discussion}

This study is the largest to date to examine polymorphisms of the $C A S R$ gene in patients receiving dialysis, with nearly half of the participants in the EVOLVE trial evaluated $(7, \underline{8})$. The hypothesis that SNPs in CASR would be associated with responsiveness to cinacalcet was on the basis of the allosteric activation of the receptor by cinacalcet. A previous study of seven patients undergoing hemodialysis demonstrated that one patient homozygous for the missense CASR allele (rs1042636) had a more dramatic PTH lowering response to cinacalcet (13). We found an association of this same SNP with baseline PTH in the EA population, but did not find any association with change in PTH. However, we did identify another SNP, rs9740, located in the 3' untranslated region to be marginally associated with an interaction between the SNP and change in calcium with cinacalcet in both the AfAn and EA populations. As shown in Figure 2, C and D, the difference in the percent decrease in calcium in response to cinacalcet in the AA and AG/GG genotype is $4 \%$ and $2 \%$, respectively. These results suggest a possible role of polymorphisms in the CASR gene in the hypocalcemic response to cinacalcet.

The CASR gene is a member of the superfamily of G-protein coupled receptors with a very large extracellular domain, seven membrane spanning segments, and a relatively large cytoplasmic domain. Extracellular calcium binds to multiple sites on the receptor, leading to conformational changes that result in activation of cell signaling and suppression of PTH secretion (21). Over 400 mutations in the gene have been identified throughout the receptor (http://www.casrdb.mcgill.ca/). The more severe phenotypes of autosomal dominant familial hypocalciuric hypercalcemia and autosomal recessive neonatal severe hyperparathyroidism are because of inactivating mutations; activating mutations can lead to autosomal dominant hypocalcemia (reviewed in Pollak et al. [22]).

Multiple studies have demonstrated an association of SNPs in the CASR with serum calcium concentrations. Scillitani et al. $(\underline{23})$ in a cohort of 377 Italian participants without CKD found that variants in the same three missense CASR SNPs examined in this study were responsible for $16.5 \%$ of the variance in serum ionized calcium. Homozygosity for the major allele in rs 1801725 and rs 1801726 was associated with higher ionized calcium, whereas homozygosity for the major allele in rs 1042636 was associated with lower ionized calcium. In one genome-wide association study, rs 1801725 was associated with $1.26 \%$ of the serum calcium variance in EA, and rs17251221 (in high LD with rs1801725) was also associated with 
serum calcium in Asian Indians (24). A more recent genome-wide association study in EA reported genome-wide significant association of serum calcium with rs 73186030 , also in high LD with rs 1801725 (25). Additional studies also found association of rs 1801725 with serum calcium in Canadian women (14) and a white cohort from the Atherosclerosis Risk in Communities study (26). In this study, we also detected association of rs1801725 with serum calcium, in addition to associations of these missense SNPs with baseline PTH in the EA population. The association of these SNPs with PTH, in addition to calcium, may be because of the many factors that alter the calcium-PTH relationship in patients with CKD-MBD. The MAF for all three of these missense mutations was also low, especially in those of AfAn, likely limiting the power for detecting stronger associations with serum calcium. A modest association was also identified with the CASR SNPs and baseline calcium and FGF23 levels in the AfAn population for intronic SNPs, reflecting likely epigenetic effects, although these have not been elucidated for the CASR gene to date (27)

We found different associations of the SNPs in CASR in the EA and AfAn populations. In the EA population, baseline serum PTH, BALP, and phosphate were associated with missense SNPs. In contrast, in the AfAn population, baseline serum calcium, and FGF23 were associated with intronic CASR SNPs. This could be due, in part, to differences in phenotype by race or to differences in allele frequencies for most of the SNPs between the EA and AfAn populations, with the minor allele being different for rs 1393199 . In patients receiving hemodialysis, AfAn patients generally have higher PTH compared with EA patients at similar levels of bone turnover (28). Another study found that optimal PTH targets for bone remodeling may be different in EA and AfAn patients (29). Among participants in the Chronic Renal Insufficiency Cohort study, black participants had higher concentrations of serum phosphate, alkaline phosphatase, FGF23, and PTH, and lower 24-hour urinary excretion of calcium and phosphorus (10). These differences suggest that differences in CASR polymorphisms may contribute to phenotypic differences in CKD-MBD in EA and AfAn populations.

Our study identified an association with a group of intronic SNPs in high LD in the CASR gene and a higher risk of fracture in the EA population that was attenuated with cinacalcet treatment. The consistency of these results across SNPs in high LD increases the confidence in our findings. To our knowledge, no study has previously identified an association with these SNPs and fracture, and thus the results must be validated. In the EVOLVE trial, clinically symptomatic adjudicated fractures were found in $13 \%$ of the participants during the study, and were reduced with cinacalcet treatment (20). However, only $15.6 \%$ of the fractures were hip fractures (20). Unfortunately, the majority of cohort studies that may have access to DNA samples have only assessed hip fracture, and thus our results may not be readily validated. The CASR gene is important in fetal bone development; conditional deletion of CASR in early osteoblasts leads to altered bone phenotype, although the results vary depending on the construct used (30). Other studies also suggest a regulatory role of calcium in PTH-induced bone resorption and formation (31) and regulation of FGF23 secretion $(32,33)$, but whether this is mediated by $C A S R$ is not yet known. Taken together, these results suggest that further exploration of the role of $C A S R$ polymorphisms on calcium sensing by osteoblasts and the function of the receptor in bone is warranted.

This study has both strengths and weaknesses. First, it is the largest genetic study in patients on dialysis to date. Second, SNPs across the CASR gene were evaluated, including missense and intronic SNPs previously reported in the literature. Third, a comprehensive set of CKD-MBD manifestations were tested for association with these SNPs. One weakness of the study is the modest sample size, although it is the study with the largest sample size examining SNPs and mineral metabolism to date. Thus, some associations may have been missed, particularly in the smaller AfAn population. To ensure complete coverage of CASR, a dense set of SNPs were genotyped. Because of the LD among these SNPs, we did not correct for the number of SNPs genotyped. Thus, some results could be potential false positive results. Although only clinical characteristics known to be affected by polymorphisms in the CASR gene were tested, these results need to be replicated in independent samples. 
In summary, we identified several SNPs in $C A S R$ that were associated with baseline biochemical values of CKD-MBD, with distinct differences in EA and AfAn populations but no association with $V D R$. Of importance, only one SNP, rs9740, showed an interaction between decrease in corrected serum calcium and treatment with cinacalcet in both populations. An additional observation of an association between a group of intronic SNPs in high LD and risk of fracture in the EA population requires further validation. These associations, if validated, may partly explain differences in the clinical manifestations of CKD-MBD between EA and AfAn populations, and in the biochemical response to cinacalcet in many patients.

\section{Disclosures}

S.M.M. and G.M.C. served on the Academic Executive Committee for the Evaluation of Cinacalcet Hcl Therapy to Lower Cardiovascular Events (EVOLVE) trial and the current Publication Committee for the EVOLVE trial. S.A., J.L., and G.M.C. have received funding from Amgen to conduct secondary analyses of the EVOLVE trial. S.M.M. has received honoraria from Merck. M.V. receives salary and stocks from Invitae Corporation.

\section{Supplementary Material}

\section{Supplemental Data:}

\section{Acknowledgments}

The authors thank Pam Minick and Robert Orr for DNA isolation, Dr. Howard Edenberg and Dr. Xiaoling Xuei for genotyping, and the assistance of Amgen employees Dr. Xiaoye Ma, Dr. Yun Chun, and Dr. Bastian Dehmel for help in extracting clinical data from the larger Evaluation of Cinacalcet $\mathrm{HCl}$ Therapy to Lower Cardiovascular Events (EVOLVE) trial dataset. The authors are grateful for the leadership of Dr. Pat Parfrey and all of the members of the EVOLVE trial executive committee, the study site investigators, and the patients who participated in the EVOLVE trial.

This work was supported by National Institute of Diabetes and Digestive and Kidney Diseases grants R01DK100306 (to S.M.M.) and K23-DK084260 (to B.S.D.). The samples are maintained in a facility constructed with support from Research Facilities Improvement Program grant no. C06 RR020128-01 from the National Center for Research Resources, National Institutes of Health.

\section{Footnotes}

Published online ahead of print. Publication date available at www.cjasn.org.

See related editorial, "The Potential of Pharmacogenomics to Advance Kidney Disease Treatment," on pages 1035-1037.

This article contains supplemental material online at http://cjasn.asnjournals.org/lookup/suppl/doi:10.2215 ICJN.11141016/-/DCSupplemental.

\section{References}

1. Moe SM, Drüeke T, Lameire N, Eknoyan G.: Chronic kidney disease-mineral-bone disorder: A new paradigm. Adv Chronic Kidney Dis 14: 3-12, 2007 [PubMed: 17200038]

2. Moe S, Drüeke T, Cunningham J, Goodman W, Martin K, Olgaard K, Ott S, Sprague S, Lameire N, Eknoyan G; Kidney Disease: Improving Global Outcomes (KDIGO) : Definition, evaluation, and classification of renal osteodystrophy: A position statement from kidney disease: Improving Global Outcomes (KDIGO). Kidney Int 69: 1945-1953, 2006 [PubMed: 16641930] 
3. Palmer SC, Hayen A, Macaskill P, Pellegrini F, Craig JC, Elder GJ, Strippoli GF.: Serum levels of phosphorus, parathyroid hormone, and calcium and risks of death and cardiovascular disease in individuals with chronic kidney disease: A systematic review and meta-analysis. JAMA 305: 1119-1127, 2011 [PubMed: 21406649]

4. Sprague SM, Moe SM.: The case for routine parathyroid hormone monitoring. Clin J Am Soc Nephrol 8: 313-318, 2013 [PMCID: PMC3562858] [PubMed: 23037984]

5. Moe SM, Chertow GM, Coburn JW, Quarles LD, Goodman WG, Block GA, Drüeke TB, Cunningham J, Sherrard DJ, McCary LC, Olson KA, Turner SA, Martin KJ.: Achieving NKF-K/DOQI bone metabolism and disease treatment goals with cinacalcet HCl. Kidney Int 67: 760-771, 2005 [PubMed: 15673327]

6. Block GA, Martin KJ, de Francisco AL, Turner SA, Avram MM, Suranyi MG, Hercz G, Cunningham J, Abu-Alfa AK, Messa P, Coyne DW, Locatelli F, Cohen RM, Evenepoel P, Moe SM, Fournier A, Braun J, McCary LC, Zani VJ, Olson KA, Drüeke TB, Goodman WG.: Cinacalcet for secondary hyperparathyroidism in patients receiving hemodialysis. N Engl J Med 350: 1516-1525, 2004 [PubMed: 15071126]

7. Chertow GM, Block GA, Correa-Rotter R, Drüeke TB, Floege J, Goodman WG, Herzog CA, Kubo Y, London GM, Mahaffey KW, Mix TC, Moe SM, Trotman ML, Wheeler DC, Parfrey PS; EVOLVE Trial Investigators.$:$ Effect of cinacalcet on cardiovascular disease in patients undergoing dialysis. N Engl J Med 367: 2482-2494, 2012 [PubMed: 23121374]

8. Chertow GM, Correa-Rotter R, Block GA, Drueke TB, Floege J, Goodman WG, Herzog CA, Kubo Y, London GM, Mahaffey KW, Mix TC, Moe SM, Wheeler DC, Parfrey PS.: Baseline characteristics of subjects enrolled in the Evaluation of Cinacalcet $\mathrm{HCl}$ Therapy to Lower Cardiovascular Events (EVOLVE) trial. Nephrol Dial Transplant 27: 2872-2879, 2012 [PubMed: 22529163]

9. Ennis J, Worcester E, Coe F.: Contribution of calcium, phosphorus and 25-hydroxyvitamin D to the excessive severity of secondary hyperparathyroidism in African-Americans with CKD. Nephrol Dial Transplant 27: 2847-2853, 2012 [PubMed: 22505656]

10. Gutiérrez OM, Isakova T, Andress DL, Levin A, Wolf M.: Prevalence and severity of disordered mineral metabolism in blacks with chronic kidney disease. Kidney Int 73: 956-962, 2008 [PubMed: 18256597]

11. Ertürk S, Kutlay S, Karabulut HG, Keven K, Nergizoglu G, Ates K, Bokesoy I, Duman N.: The impact of vitamin D receptor genotype on the management of anemia in hemodialysis patients. Am J Kidney Dis 40: 816-823, 2002 [PubMed: 12324918]

12. Erturk S; DialGene Consortium .: Gene polymorphism association studies in dialysis: Bone and mineral metabolism. Semin Dial 19: 232-237, 2006 [PubMed: 16689975]

13. Rothe HM, Shapiro WB, Sun WY, Chou SY.: Calcium-sensing receptor gene polymorphism Arg990Gly and its possible effect on response to cinacalcet HCl. Pharmacogenet Genomics 15: 29-34, 2005 [PubMed: $15864123]$

14. Cole DE, Peltekova VD, Rubin LA, Hawker GA, Vieth R, Liew CC, Hwang DM, Evrovski J, Hendy GN.: A986S polymorphism of the calcium-sensing receptor and circulating calcium concentrations. Lancet 353: 112-115, 1999 [PubMed: 10023897]

15. Miedlich S, Lamesch P, Mueller A, Paschke R.: Frequency of the calcium-sensing receptor variant A986S in patients with primary hyperparathyroidism. Eur J Endocrinol 145: 421-427, 2001 [PubMed: 11580999] 
16. Pratt JH, Ambrosius WT, Wagner MA, Maharry K.: Molecular variations in the calcium-sensing receptor in relation to sodium balance and presence of hypertension in blacks and whites. Am J Hypertens 13: 654-658, 2000 [PubMed: 10912749]

17. Purcell S, Neale B, Todd-Brown K, Thomas L, Ferreira MA, Bender D, Maller J, Sklar P, de Bakker PI, Daly MJ, Sham PC.: PLINK: A tool set for whole-genome association and population-based linkage analyses. Am J Hum Genet 81: 559-575, 2007 [PMCID: PMC1950838] [PubMed: 17701901]

18. Riccardi D, Valenti G.: Localization and function of the renal calcium-sensing receptor. Nat Rev Nephrol 12: 414-425, 2016 [PubMed: 27157444]

19. Chertow GM, Pupim LB, Block GA, Correa-Rotter R, Drueke TB, Floege J, Goodman WG, London GM, Mahaffey KW, Moe SM, Wheeler DC, Albizem M, Olson K, Klassen P, Parfrey P.: Evaluation of cinacalcet therapy to lower cardiovascular events (EVOLVE): Rationale and design overview. Clin J Am Soc Nephrol 2: 898-905, 2007 [PubMed: 17702710]

20. Moe SM, Abdalla S, Chertow GM, Parfrey PS, Block GA, Correa-Rotter R, Floege J, Herzog CA, London GM, Mahaffey KW, Wheeler DC, Dehmel B, Goodman WG, Drüeke TB; Evaluation of Cinacalcet $\mathrm{HCl}$ Therapy to Lower Cardiovascular Events (EVOLVE) Trial Investigators .: Effects of Cinacalcet on fracture events in patients receiving hemodialysis: The EVOLVE Trial. J Am Soc Nephrol 26: 1466-1475, 2015 [PMCID: PMC4446874] [PubMed: 25505257]

21. Conigrave AD, Ward DT.: Calcium-sensing receptor (CaSR): Pharmacological properties and signaling pathways. Best Pract Res Clin Endocrinol Metab 27: 315-331, 2013 [PubMed: 23856262]

22. Pollak MR, Seidman CE, Brown EM.: Three inherited disorders of calcium sensing. Medicine (Baltimore) 75: 115-123, 1996 [PubMed: 8965680]

23. Scillitani A, Guarnieri V, De Geronimo S, Muscarella LA, Battista C, D’Agruma L, Bertoldo F, Florio C, Minisola S, Hendy GN, Cole DE.: Blood ionized calcium is associated with clustered polymorphisms in the carboxyl-terminal tail of the calcium-sensing receptor. J Clin Endocrinol Metab 89: 5634-5638, 2004 [PubMed: 15531522]

24. Kapur K, Johnson T, Beckmann ND, Sehmi J, Tanaka T, Kutalik Z, Styrkarsdottir U, Zhang W, Marek D, Gudbjartsson DF, Milaneschi Y, Holm H, Diiorio A, Waterworth D, Li Y, Singleton AB, Bjornsdottir US, Sigurdsson G, Hernandez DG, Desilva R, Elliott P, Eyjolfsson GI, Guralnik JM, Scott J, Thorsteinsdottir U, Bandinelli S, Chambers J, Stefansson K, Waeber G, Ferrucci L, Kooner JS, Mooser V, Vollenweider P, Beckmann JS, Bochud M, Bergmann S.: Genome-wide meta-analysis for serum calcium identifies significantly associated SNPs near the calcium-sensing receptor (CASR) gene. PLoS Genet 6: e1001035, 2010 [PMCID: PMC2908705] [PubMed: 20661308]

25. Robinson-Cohen C, Lutsey PL, Kleber ME, Nielson CM, Mitchell BD, Bis JC, Eny KM, Portas L, Eriksson J, Lorentzon M, Koller DL, Milaneschi Y, Teumer A, Pilz S, Nethander M, Selvin E, Tang W, Weng LC, Wong HS, Lai D, Peacock M, Hannemann A, Völker U, Homuth G, Nauk M, Murgia F, Pattee JW, Orwoll E, Zmuda JM, Riancho JA, Wolf M, Williams F, Penninx B, Econs MJ, Ryan KA, Ohlsson C, Paterson AD, Psaty BM, Siscovick DS, Rotter JI, Pirastu M, Streeten E, März W, Fox C, Coresh J, Wallaschofski H, Pankow JS, de Boer IH, Kestenbaum B.: Genetic variants associated with circulating parathyroid hormone [published online ahead of print December 7, 2016]. J Am Soc Nephrol doi:10.1681/ASN.2016010069 [PMCID: PMC5407713] [PubMed: 27927781]

26. Rooney MR, Pankow JS, Sibley SD, Selvin E, Reis JP, Michos ED, Lutsey PL.: Serum calcium and incident type 2 diabetes: The Atherosclerosis Risk in Communities (ARIC) study. Am J Clin Nutr 104: 1023-1029, 2016 [PMCID: PMC5039808] [PubMed: 27510541] 
27. Breitwieser GE: The calcium sensing receptor life cycle: Trafficking, cell surface expression, and degradation. Best Pract Res Clin Endocrinol Metab 27: 303-313, 2013 [PubMed: 23856261]

28. Sawaya BP, Butros R, Naqvi S, Geng Z, Mawad H, Friedler R, Fanti P, Monier-Faugere MC, Malluche HH.: Differences in bone turnover and intact PTH levels between African American and Caucasian patients with end-stage renal disease. Kidney Int 64: 737-742, 2003 [PubMed: 12846773]

29. Moore C, Yee J, Malluche H, Rao DS, Monier-Faugere MC, Adams E, Daramola-Ogunwuyi O, Fehmi H, Bhat S, Osman-Malik Y.: Relationship between bone histology and markers of bone and mineral metabolism in African-American hemodialysis patients. Clin J Am Soc Nephrol 4: 1484-1493, 2009 [PMCID: PMC2736690] [PubMed: 19713297]

30. Riccardi D, Brennan SC, Chang W.: The extracellular calcium-sensing receptor, CaSR, in fetal development. Best Pract Res Clin Endocrinol Metab 27: 443-453, 2013 [PMCID: PMC4462341] [PubMed: 23856271]

31. Xue Y, Xiao Y, Liu J, Karaplis AC, Pollak MR, Brown EM, Miao D, Goltzman D.: The calciumsensing receptor complements parathyroid hormone-induced bone turnover in discrete skeletal compartments in mice. Am J Physiol Endocrinol Metab 302: E841-E851, 2012 [PMCID: PMC3330707] [PubMed: 22275754]

32. Moe SM, Chen NX, Newman CL, Gattone VH 2nd, Organ JM, Chen X, Allen MR.: A comparison of calcium to zoledronic acid for improvement of cortical bone in an animal model of CKD. J Bone Miner Res 29: 902-910, 2014 [PMCID: PMC3940692] [PubMed: 24038306]

33. Moe SM, Chertow GM, Parfrey PS, Kubo Y, Block GA, Correa-Rotter R, Drüeke TB, Herzog CA, London GM, Mahaffey KW, Wheeler DC, Stolina M, Dehmel B, Goodman WG, Floege J; Evaluation of Cinacalcet $\mathrm{HCl}$ Therapy to Lower Cardiovascular Events (EVOLVE) Trial Investigators* : Cinacalcet, fibroblast growth factor-23, and cardiovascular disease in hemodialysis: The Evaluation of Cinacalcet $\mathrm{HCl}$ Therapy to Lower Cardiovascular Events (EVOLVE) Trial. Circulation 132: 27-39, 2015 [PubMed: 26059012]

Figures and Tables 


\section{Figure 1.}
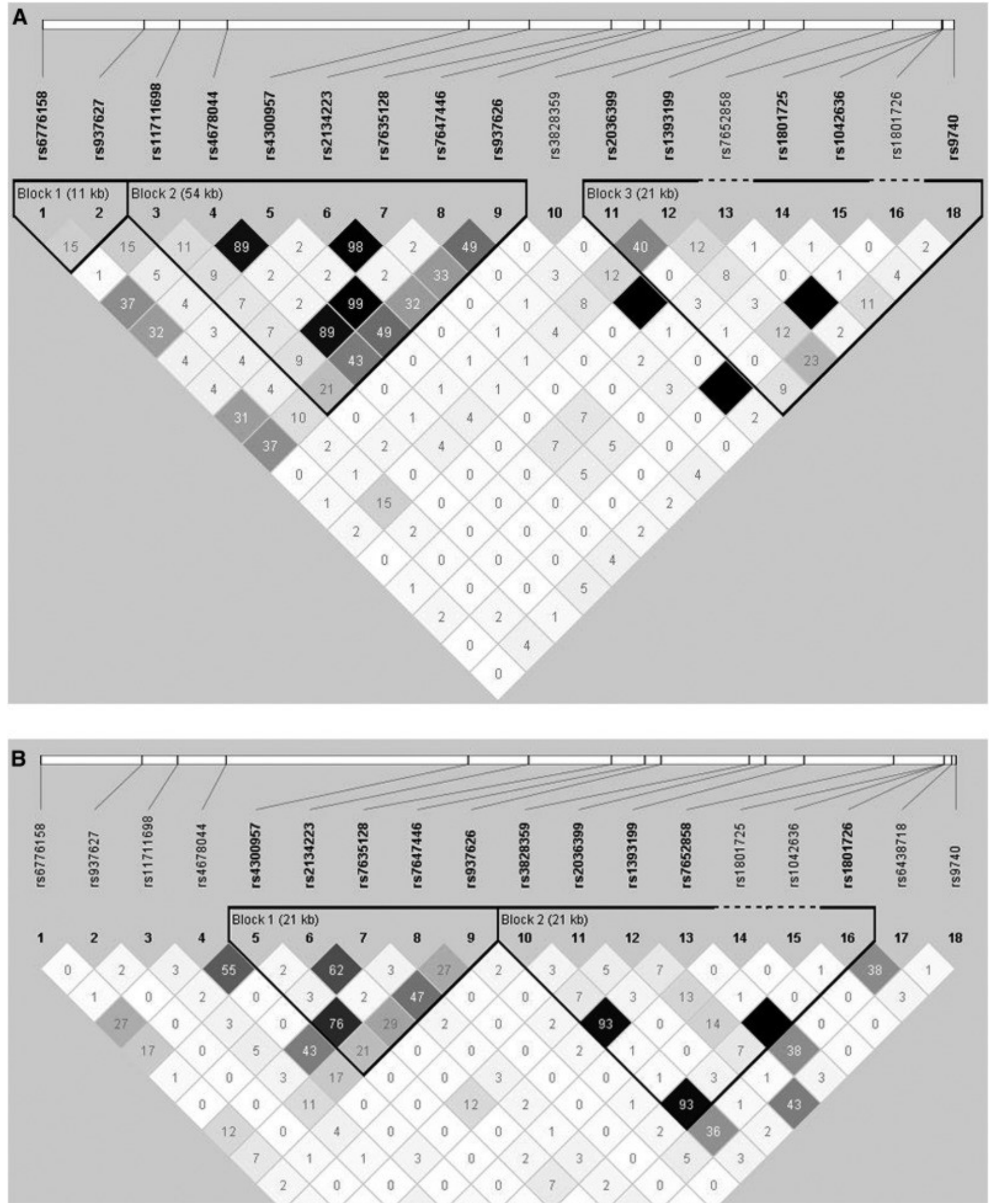

Open in a separate window

Linkage disequilibrium (LD) maps for the calcium-sensing receptor (CASR). LD maps for the CASR single nucleotide polymorphisms (SNPs) examined in (A) the European ancestry population and (B) the African ancestry population. Numeric values represent pairwise LD as measured by $r^{2}$. SNPs in high LD are represented by darker squares. 


\section{Table 1.}

Demographic and baseline laboratory values for DNA cohort compared with the primary EVOLVE trial $(\underline{7}, \underline{8}, \underline{33}, 34)$ 


\begin{tabular}{|c|c|c|c|c|}
\hline Characteristic & All, $n=1812$ & EA, $n=1067$ & AfAn, $n=405$ & $\begin{array}{l}\text { EVOLVE Cohort, } \\
\qquad n=3883\end{array}$ \\
\hline Cinacalcet use, $n(\%)$ & $918(50.7)$ & $551(51.6)$ & $203(50.1)$ & $970(50.7)$ \\
\hline \multicolumn{5}{|l|}{ Demographics } \\
\hline Age, yr, mean (SD) & $54.3(14.1)$ & $56.4(14.0)$ & $52.2(13.4)$ & $54.4(14.4)$ \\
\hline Sex, women, $n(\%)$ & $718(39.6)$ & $406(38.0)$ & $171(42.2)$ & $1578(40.6)$ \\
\hline \multicolumn{5}{|l|}{ Ethnicity, n (\%) } \\
\hline EA & & $1067(58.9)$ & & $2241(57.7)$ \\
\hline AfAn & & & $405(22.3)$ & $837(21.6)$ \\
\hline Other & $340(18.8)$ & & & $805(20.7)$ \\
\hline Dialysis vintage, mo & & & & $45.0(9.0 ; 146.0)$ \\
\hline$<2 \mathrm{yr}, n(\%)$ & $527(29.1)$ & $315(29.5)$ & $138(34.1)$ & \\
\hline 2 to $<5 \mathrm{yr}, n(\%)$ & $601(33.2)$ & $340(31.9)$ & $141(34.8)$ & \\
\hline$\geq 5 \mathrm{yr}, n(\%)$ & $684(37.7)$ & $412(38.6)$ & $126(31.1)$ & \\
\hline Diabetes, type 1 or $2, n(\%)$ & $588(32.5)$ & $295(27.6)$ & $181(44.7)$ & $1302(33.5)$ \\
\hline History of parathyroidectomy, $n(\%)$ & $93(5.1)$ & $64(6.0)$ & $9(2.2)$ & $176(4.5)$ \\
\hline History of fracture, $n(\%)$ & $349(19.3)$ & $214(20.1)$ & $70(17.3)$ & $769(19.8)$ \\
\hline \multicolumn{5}{|l|}{ Baseline drug use } \\
\hline Calcium-based phosphate binders, $n(\%)$ & $1014(56.0)$ & $669(62.7)$ & $150(37.0)$ & $2025(59.8)$ \\
\hline Baseline vitamin $\mathrm{D}, n(\%)$ & $1134(62.6)$ & $650(60.9)$ & $314(77.5)$ & $2232(57.5)$ \\
\hline \multicolumn{5}{|l|}{ Baseline laboratory values } \\
\hline Corrected calcium, mg/dl, mean (SD) & $9.8(0.70)$ & $9.8(0.70)$ & $9.8(0.59)$ & $9.8(0.7)$ \\
\hline Phosphorus, mg/dl, mean (SD) & $6.5(1.4)$ & $6.6(1.5)$ & $6.3(1.4)$ & $6.5(1.4)$ \\
\hline Intact PTH, pg/ml, median (p10; p90) & $\begin{array}{c}691(363 ; \\
1662)\end{array}$ & $\begin{array}{c}720(370 \\
1702)\end{array}$ & $\begin{array}{c}611(337 ; \\
1410)\end{array}$ & $\begin{array}{c}691.8(363.0 \\
1694.0)\end{array}$ \\
\hline FGF23, pg/ml, median (p10; p90) & $\begin{array}{c}5670(300 \\
18,240)\end{array}$ & $\begin{array}{c}5970(320 \\
19,105)\end{array}$ & $\begin{array}{c}5080(350 \\
17,000)\end{array}$ & $5590(580 ; 19,540)$ \\
\hline $\begin{array}{l}\text { Bone alkaline phosphatase, } \mu \mathrm{g} / \mathrm{L} \text {, } \\
\text { median (p10; p90) }\end{array}$ & $\begin{array}{l}22.3(11.0 \\
\quad 62.2)\end{array}$ & $\begin{array}{l}21.2(10.6 ; \\
57.5)\end{array}$ & $\begin{array}{l}22.9(11.3 \\
\quad 60.1)\end{array}$ & $23.0(11.5 ; 68.1)$ \\
\hline $\begin{array}{l}\text { N-telopeptide, nmol BCE/L, median } \\
\text { (p10; p90) }\end{array}$ & $249(76 ; 815)$ & $251(75 ; 803)$ & $227(67 ; 628)$ & $255(80 ; 884.9)$ \\
\hline $\begin{array}{l}\text { 1,25 dihydroxy vitamin D level, } \mathrm{ng} / \mathrm{ml} \text {, } \\
\text { median (p10; p90) }\end{array}$ & $16(8 ; 33)$ & $16(8 ; 32)$ & $13.0(7 ; 25)$ & $17.0(8 ; 37)$ \\
\hline \multicolumn{5}{|l|}{ Percent change in laboratory values } \\
\hline $\begin{array}{l}\text { Percent change in corrected calcium, } \\
\text { mean (SD) }\end{array}$ & $-4.2(8.8)$ & $-4.6(8.8)$ & $-3.3(8.4)$ & \\
\hline $\begin{array}{l}\text { Percent change in PTH, median (p10; } \\
\text { p90) }\end{array}$ & $\begin{array}{c}-23.5(-77.1 \\
39.6)\end{array}$ & $\begin{array}{c}-25.2(-78.7 \\
36.5)\end{array}$ & $\begin{array}{c}-27.7(-74.3 \\
43.1)\end{array}$ & \\
\hline $\begin{array}{l}\text { Percent change in FGF23, median (p10; } \\
\text { p90) }\end{array}$ & $\begin{array}{c}-23.8(-80.4 \\
93.0)\end{array}$ & $\begin{array}{c}-24.6(-79.8 \\
85.9)\end{array}$ & $\begin{array}{c}-21.4(-80.7 \\
137.2)\end{array}$ & \\
\hline
\end{tabular}


Calcium-Sensing Receptor Genotype and Response to Cinacalcet in Patie... https://www.ncbi.nlm.nih.gov/pmc/articles/PMC5498355/?report=printable

\section{Characteristic}

Percent change in phosphorus, mean (SD)

\section{All, $n=1812$ \\ EA, $n=1067$ \\ AfAn, $n=405$}

$-8.2(23.2) \quad-8.6(22.2)$
Open in a separate window

EVOLVE, Evaluation of Cinacalcet HCl Therapy to Lower Cardiovascular Events; EA, European ancestry; AfAn, African ancestry; PTH, parathyroid hormone; p10, 10th percentile; p90, 90th percentile; FGF23, fibroblast growth factor 23 . 
Table 2.

Associations of CASR single nucleotide polymorphisms with baseline biochemistries in European ancestry

\begin{tabular}{|c|c|c|c|c|c|c|c|c|c|c|c|}
\hline \multirow[t]{2}{*}{ SNP } & \multirow[t]{2}{*}{ Function } & \multirow[t]{2}{*}{ MAF } & \multirow{2}{*}{$\begin{array}{l}\text { Calcium } \\
P \text { Value }\end{array}$} & \multicolumn{3}{|c|}{ PTH } & \multirow{2}{*}{$\begin{array}{c}\text { FGF23 } \\
P \\
\text { Value }\end{array}$} & \multicolumn{3}{|c|}{ BALP } & \multirow[t]{2}{*}{ Phosphorus } \\
\hline & & & & $\begin{array}{c}P \\
\text { Value }\end{array}$ & $\beta$ & $\begin{array}{c}95 \% \\
\text { CI }\end{array}$ & & $\begin{array}{c}P \\
\text { Value }\end{array}$ & $\beta$ & $\begin{array}{c}95 \% \\
\text { CI }\end{array}$ & \\
\hline rs6776158 & $5^{\prime}$ & 0.36 & 0.74 & 0.75 & & & 0.56 & 0.10 & & & 0.51 \\
\hline rs937627 & Intron & 0.23 & 0.69 & 0.44 & & & 0.71 & 0.50 & & & 0.86 \\
\hline rs11711698 & Intron & 0.35 & 0.72 & 0.15 & & & 0.45 & 0.16 & & & 0.78 \\
\hline rs4678044 & Intron & 0.17 & 0.33 & 0.68 & & & 0.32 & 0.50 & & & 0.54 \\
\hline rs4300957 & Intron & 0.17 & 0.59 & 0.63 & & & 0.10 & 0.57 & & & 0.59 \\
\hline rs 2134223 & Intron & 0.12 & 0.53 & 0.52 & & & 0.42 & 0.02 & 0.07 & $\begin{array}{c}0.01 \\
\text { to } \\
0.13\end{array}$ & 0.81 \\
\hline rs 7635128 & Intron & 0.12 & 0.60 & 0.54 & & & 0.35 & 0.01 & 0.08 & $\begin{array}{c}0.02 \\
\text { to } \\
0.14\end{array}$ & 0.98 \\
\hline rs7647446 & Intron & 0.17 & 0.49 & 0.53 & & & 0.10 & 0.53 & & & 0.60 \\
\hline rs937626 & Intron & 0.29 & 0.91 & 0.94 & & & 0.51 & 0.02 & 0.05 & $\begin{array}{c}0.01 \\
\text { to } \\
0.10\end{array}$ & 0.69 \\
\hline rs3828359 & Intron & 0.05 & 0.17 & 0.09 & & & 0.94 & 0.84 & & & 0.57 \\
\hline rs2036399 & Intron & 0.14 & 0.38 & 0.54 & & & 0.62 & 0.98 & & & 0.59 \\
\hline rs1393199 & Intron & 0.30 & 0.90 & 0.45 & & & 0.59 & 0.55 & & & 0.80 \\
\hline rs7652858 & Intron & 0.05 & 0.17 & 0.09 & & & 0.93 & 0.83 & & & 0.56 \\
\hline rs1801725 & $\begin{array}{c}\text { Missense } \\
\text { A986S }\end{array}$ & 0.16 & 0.57 & 0.02 & 0.06 & $\begin{array}{c}0.01 \text { to } \\
0.11\end{array}$ & 0.20 & 0.58 & & & 0.03 \\
\hline rs1042636 & $\begin{array}{c}\text { Missense } \\
\text { R990G }\end{array}$ & 0.07 & 0.11 & 0.01 & -0.10 & $\begin{array}{c}-0.16 \\
\text { to } \\
-0.03\end{array}$ & 0.14 & 0.20 & & & 0.41 \\
\hline rs1801726 & $\begin{array}{c}\text { Missense } \\
\text { E1011Q }\end{array}$ & 0.05 & 0.17 & 0.09 & & & 0.94 & 0.84 & & & 0.57 \\
\hline rs6438718 & $3^{\prime}$ & 0.00 & & & & & & & & & \\
\hline rs9740 & $3^{\prime}$ & 0.36 & 0.42 & 0.69 & & & 0.71 & 0.84 & & & 0.54 \\
\hline
\end{tabular}

$P$ values for each clinical phenotype are presented for each SNP for EA participants. $\beta$ values and $95 \%$ CIs are provided for SNPs with $P<0.05$. The direction of $\beta$ reflects the effect of one copy of the minor allele. The calcium was corrected for albumin. Covariates for calcium were baseline calcium binder use, age, PTH, phosphorus, NTX, and bone alkaline phosphorus. Covariates for PTH were age, bone alkaline phosphorus, NTX, baseline vitamin D use, and 
calcium. Covariates for FGF23 were age, sex, dialysis duration, bone alkaline phosphorus, calcium, phosphorus, and PTH. Covariates for phosphorus were age, bone alkaline phosphorus, calcium, PTH, and baseline vitamin D use. Covariates for bone alkaline phosphorus were age, sex, dialysis duration, PTH, and NTX. Blank cells are due to $\mathrm{MAF}<0.05$. $C A S R$, calcium-sensing receptor; SNP, single nucleotide polymorphism; MAF, minor allele frequency; PTH, parathyroid hormone; FGF23, fibroblast growth factor 23; BALP, bone-specific alkaline phosphatase; $95 \%$ CI, 95\% confidence interval; NTX, N-telopeptide; EA, European ancestry. 
Table 3

Associations of CASR single nucleotide polymorphisms with baseline biochemistries in African ancestry

\begin{tabular}{|c|c|c|c|c|c|c|c|c|c|c|c|c|c|}
\hline \multirow[t]{2}{*}{ SNP } & \multirow[t]{2}{*}{ Function } & \multirow[t]{2}{*}{ MAF } & \multicolumn{3}{|c|}{ Calcium } & \multirow[t]{2}{*}{ PTH } & \multicolumn{3}{|c|}{ FGF23 } & \multirow{2}{*}{$\begin{array}{c}\text { BALP } \\
\quad P \\
\text { Value }\end{array}$} & \multicolumn{3}{|c|}{ Phosphorus } \\
\hline & & & $\begin{array}{c}P \\
\text { Value }\end{array}$ & $\beta$ & $\begin{array}{c}95 \% \\
\text { CI }\end{array}$ & & $\begin{array}{c}P \\
\text { Value }\end{array}$ & $\beta$ & $\begin{array}{c}95 \% \\
\text { CI }\end{array}$ & & $\begin{array}{c}P \\
\text { Value }\end{array}$ & $\beta$ & $\begin{array}{c}95 \% \\
\text { CI }\end{array}$ \\
\hline rs6776158 & $5^{\prime}$ & 0.39 & 0.63 & & & 0.34 & 0.33 & & & 0.89 & 0.62 & & \\
\hline rs937627 & Intron & 0.09 & 0.17 & & & 0.40 & 0.23 & & & 0.65 & 0.83 & & \\
\hline rs11711698 & Intron & 0.17 & 0.89 & & & 0.95 & 0.55 & & & 0.28 & 0.02 & -0.04 & $\begin{array}{c}-0.08 \\
\text { to } \\
-0.01\end{array}$ \\
\hline rs4678044 & Intron & 0.15 & 0.23 & & & 0.46 & 0.16 & & & 0.46 & 0.80 & & \\
\hline rs4300957 & Intron & 0.11 & 0.01 & -0.02 & $\begin{array}{c}-0.03 \\
\text { to } \\
-0.01\end{array}$ & 0.76 & 0.04 & 0.23 & $\begin{array}{c}0.01 \\
\text { to } \\
0.45\end{array}$ & 0.65 & 0.99 & & \\
\hline rs2134223 & Intron & 0.16 & 0.09 & & & 0.27 & 0.29 & & & 0.87 & 0.03 & 0.04 & $\begin{array}{c}0.003 \\
\text { to } \\
0.08\end{array}$ \\
\hline rs7635128 & Intron & 0.22 & 0.02 & 0.01 & $\begin{array}{c}0.002 \\
\text { to } 0.02\end{array}$ & 0.89 & 0.94 & & & 0.77 & 0.47 & & \\
\hline rs7647446 & Intron & 0.14 & 0.04 & -0.01 & $\begin{array}{c}-0.02 \\
\text { to } \\
-0.001\end{array}$ & 0.79 & 0.01 & 0.26 & $\begin{array}{c}0.05 \\
\text { to } \\
0.46\end{array}$ & 0.50 & 0.63 & & \\
\hline rs937626 & Intron & 0.37 & 0.77 & & & 0.66 & 0.12 & & & 0.33 & 0.32 & & \\
\hline rs3828359 & Intron & 0.18 & 0.65 & & & 0.56 & 0.11 & & & 0.22 & 0.09 & & \\
\hline rs2036399 & Intron & 0.14 & 0.71 & & & 0.74 & 0.40 & & & 0.59 & 0.97 & & \\
\hline rs1393199 & Intron & 0.26 & 0.59 & & & 0.50 & 0.21 & & & 0.15 & $<0.001$ & 0.05 & $\begin{array}{c}0.02 \\
\text { to } \\
0.08\end{array}$ \\
\hline rs7652858 & Intron & 0.17 & 0.67 & & & 0.57 & 0.20 & & & 0.12 & 0.07 & & \\
\hline rs1801725 & $\begin{array}{c}\text { Missense } \\
\text { A986S }\end{array}$ & 0.04 & & & & & & & & & & & \\
\hline rs1042636 & $\begin{array}{c}\text { Missense } \\
\text { R990G }\end{array}$ & 0.05 & 0.70 & & & 0.35 & 0.41 & & & 0.32 & 0.06 & & \\
\hline rs 1801726 & $\begin{array}{c}\text { Missense } \\
\text { E1011Q }\end{array}$ & 0.17 & 0.67 & & & 0.57 & 0.20 & & & 0.12 & 0.07 & & \\
\hline
\end{tabular}

$P$ values for each clinical phenotype are presented for each SNP for AfAn participants. $\beta$ values and $95 \%$ CIs are provided for SNPs with $P<0.05$. The direction of $\beta$ reflects the effect of one copy of the minor allele. The calcium was corrected for albumin. Covariates for calcium were baseline calcium binder use, age, PTH, phosphorus, NTX, and dialysis duration (AfAn). Covariates for PTH were age, bone alkaline phosphorus, baseline vitamin D use, and 
calcium. Covariates for FGF23 were age, sex, dialysis duration, bone alkaline phosphorus, calcium, phosphorus, and NTX. Covariates for phosphorus were age, bone alkaline phosphorus, calcium, PTH, and NTX. Covariates for bone alkaline phosphorus were age, sex, dialysis duration, PTH, baseline vitamin D use, and baseline calcium binder use. Blank cells are due to $\mathrm{MAF}<0.05$. CASR, calcium-sensing receptor; SNP, single nucleotide polymorphism; MAF, minor allele frequency; PTH, parathyroid hormone; FGF23, fibroblast growth factor 23; BALP, bone-specific alkaline phosphatase; 95\% CI, 95\% confidence interval; NTX, N-telopeptide; AfAn, African ancestry. 
Figure 2.
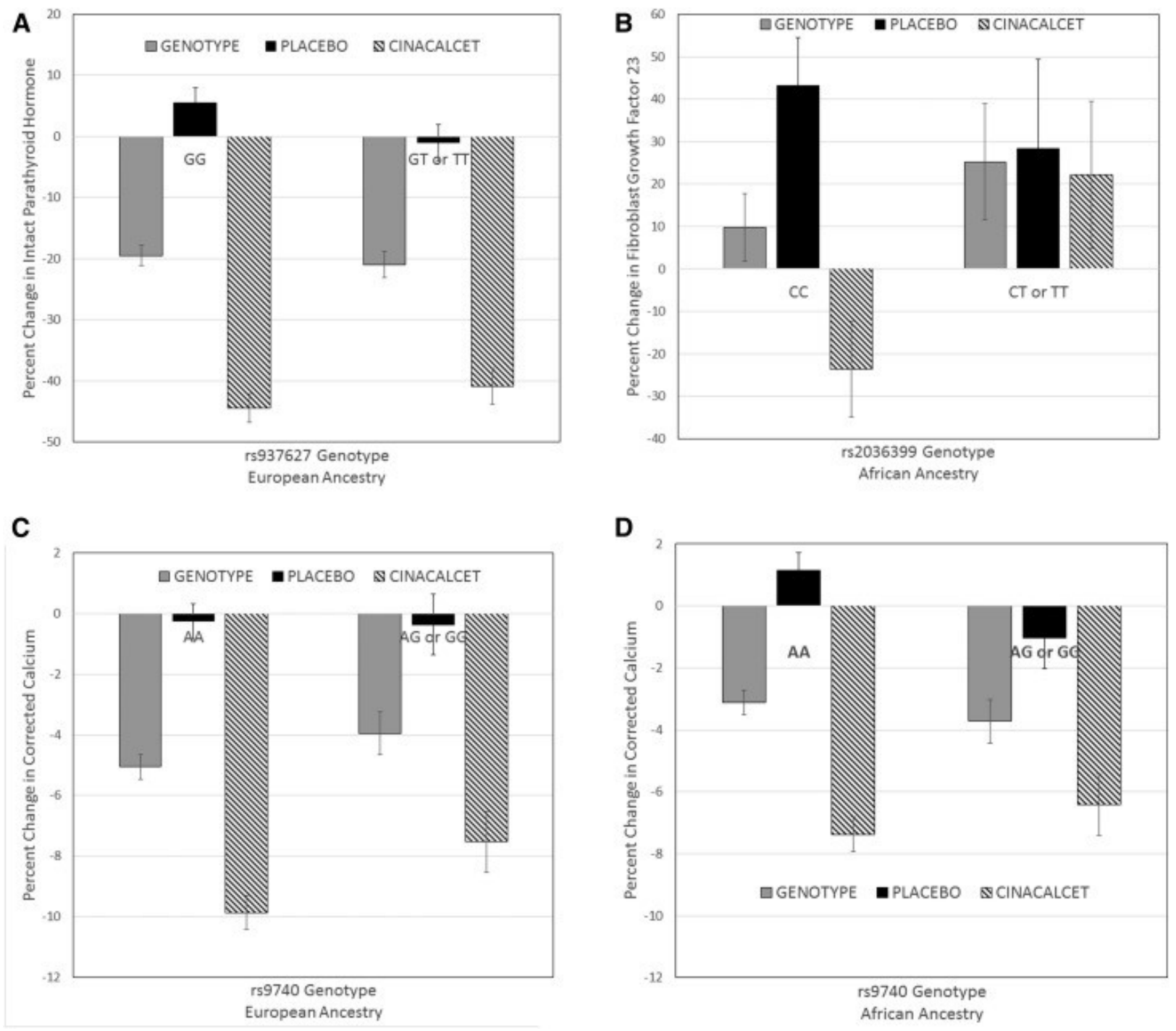

Association of CASR SNPs and percent change in biochemical measures from baseline to week 20. (A) Association of the CASR SNP rs937627 with percent change in PTH in the EA population, adjusted for baseline PTH, and age, demonstrating an association with genotype $(P<0.05)$ but no interaction with treatment $(P=0.06)$. (B) Association of the CASR SNP rs2036399 with percent change in FGF23 in the AfAn population, adjusted for baseline FGF23 and age. The results demonstrate no association with genotype $(P=0.34)$ but an interaction with treatment $(P<0.02)$. Homozygotes for the minor allele had a greater reduction in FGF23 with cinacalcet. (C) EA population and (D) AfAn population association of the CASR SNP rs9740 with percent change in calcium adjusted for age, baseline calcium, duration dialysis, baseline bone alkaline phosphatase in EA, and baseline calcium and age in AfAn. In the EA population, there was no association with genotype $(P=0.89)$, but there was a treatment-by-genotype interaction in that homozygotes for the major allele had a greater decrease in response to cinacalcet $(P=0.03)$. In the AfAn population, there was no main effect of genotype $(P=0.06)$ but a treatment-by-genotype interaction $(P=0.02)$. Gray bars. Genotype; Black bars, participants in the EVOLVE trial randomized to placebo; hashed bars, participants in the EVOLVE trial randomized to cinacalcet. AfAn, African ancestry; $C A S R$, calcium-sensing receptor; EA, European ancestry; EVOLVE, Evaluation of Cinacalcet $\mathrm{HCl}$ Therapy to Lower Cardiovascular Events; FGF23, fibroblast growth factor 23; PTH, parathyroid hormone; SNP, single nucleotide polymorphism. 


\section{Figure 3.}

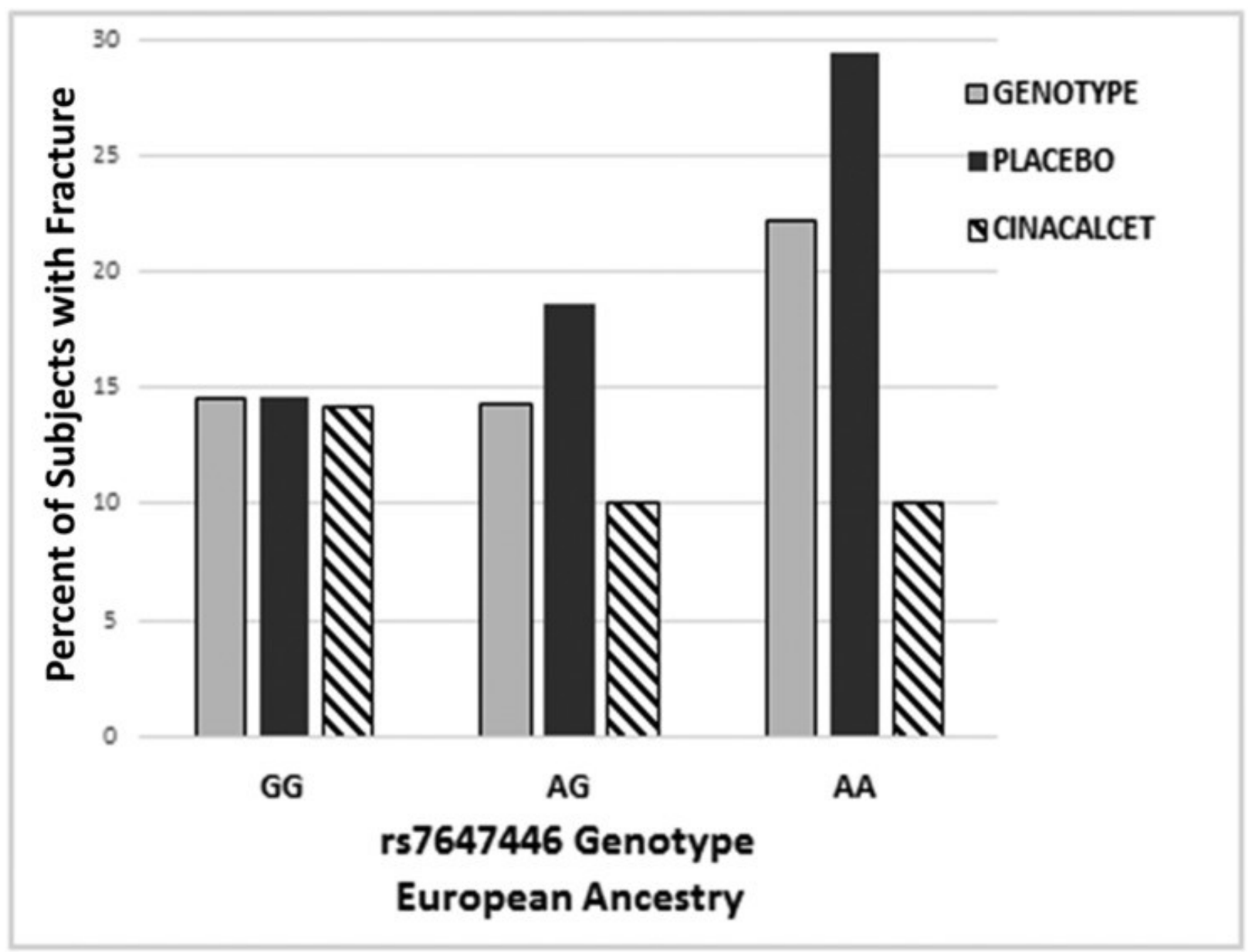

Association of CASR SNP rs7647446 with incidence of fracture during the Evaluation of Cinacalcet HCI Therapy to Lower Cardiovascular Events (EVOLVE) trial. Association of genotype and genotype-by-treatment interaction and any type of fracture during the EVOLVE trial. The results demonstrate that there is a modest but nonsignificant increased association with a higher incidence of fracture with increased number of minor A alleles $(P=0.08)$, and that the number of fractures is reduced when the individuals are treated with cinacalcet $(P=0.03)$. Similar results were observed with other single nucleotide polymorphism in high linkage disequilibrium with rs7647446. Gray bars, genotype; black bars, participants in the EVOLVE trial randomized to placebo; hashed bars, participants in the EVOLVE trial randomized to cinacalcet.

Articles from Clinical Journal of the American Society of Nephrology : CJASN are provided here courtesy of

\section{American Society of Nephrology}

